$10-15-2019$

\title{
Production of Dynein and Kinesin Motor Ensembles on DNA Origami Nanostructures for Single Molecule Observation
}

Jingjie $\mathrm{Hu}$

Smith College

Nathan Derr

Smith College, nderr@smith.edu

Follow this and additional works at: https://scholarworks.smith.edu/bio_facpubs

Part of the Biology Commons

\section{Recommended Citation}

$\mathrm{Hu}$, Jingjie and Derr, Nathan, "Production of Dynein and Kinesin Motor Ensembles on DNA Origami Nanostructures for Single Molecule Observation" (2019). Biological Sciences: Faculty Publications, Smith College, Northampton, MA.

https://scholarworks.smith.edu/bio_facpubs/68

This Article has been accepted for inclusion in Biological Sciences: Faculty Publications by an authorized administrator of Smith ScholarWorks. For more information, please contact scholarworks@smith.edu 


\title{
Video Article \\ Production of Dynein and Kinesin Motor Ensembles on DNA Origami Nanostructures for Single Molecule Observation
}

\author{
Jingjie $\mathrm{Hu}^{1}$, Nathan D. Derr ${ }^{1,2}$ \\ ${ }^{1}$ Department of Biological Sciences, Smith College \\ ${ }^{2}$ Center for Microscopy and Imaging, Smith College
}

Correspondence to: Nathan D. Derr at nderr@smith.edu

URL: https://www.jove.com/video/60369

DOI: doi:10.3791/60369

Keywords: Biochemistry, Issue 152, cytoskeleton, dynein, kinesin, molecular motors, DNA origami, single molecule methods

Date Published: 10/15/2019

Citation: Hu, J., Derr, N.D. Production of Dynein and Kinesin Motor Ensembles on DNA Origami Nanostructures for Single Molecule Observation. J. Vis. Exp. (152), e60369, doi:10.3791/60369 (2019).

\section{Abstract}

Cytoskeletal motors are responsible for a wide variety of functions in eukaryotic cells, including mitosis, cargo transport, cellular motility, and others. Many of these functions require motors to operate in ensembles. Despite a wealth of knowledge about the mechanisms of individual cytoskeletal motors, comparatively less is known about the mechanisms and emergent behaviors of motor ensembles, examples of which include changes to ensemble processivity and velocity with changing motor number, location, and configuration. Structural DNA nanotechnology, and the specific technique of DNA origami, enables the molecular construction of well-defined architectures of motor ensembles. The shape of cargo structures as well as the type, number and placement of motors on the structure can all be controlled. Here, we provide detailed protocols for producing these ensembles and observing them using total internal reflection fluorescence microscopy. Although these techniques have been specifically applied for cytoskeletal motors, the methods are generalizable to other proteins that assemble in complexes to accomplish their tasks. Overall, the DNA origami method for creating well-defined ensembles of motor proteins provides a powerful tool for dissecting the mechanisms that lead to emergent motile behavior.

\section{Video Link}

The video component of this article can be found at https://www.jove.com/video/60369/

Introduction

Dynein and kinesin are cytoskeletal motor proteins responsible for myriad functions in eukaryotic cells ${ }^{1}$. By converting the chemical energy of ATP hydrolysis into productive work, these motors translocate on microtubules to haul and distribute various intracellular cargos. They also coordinate in the massive intracellular rearrangements associated with mitosis, where they exhibit orchestrated forces that contribute to the positioning and separation of chromosomes. Structural, biochemical, and biophysical assays, including single molecule observations, have revealed the mechanisms of these motors at the individual level (well-reviewed in previous works ${ }^{2,3,4}$ ). However, many of the motors' tasks require them to work in small ensembles of both similar and mixed motor types. Comparatively less is understood about the mechanisms that coordinate the activity and ultimate emergent motility of these ensembles ${ }^{5,6}$. This knowledge gap is due, in part, to the difficulty in creating ensembles with controllable features, such as motor type and copy number. Over the past decade, the molecular construction techniques of DNA origami have been employed to solve this problem. For the microtubule based motors, some examples of these investigations include single molecule observations of ensembles of cytoplasmic dynein-1 ${ }^{7,8,9}$, intraflagellar dynein ${ }^{11}$, various kinesin motors ${ }^{12,13}$, and mixtures of both dyneins and kinesins ${ }^{7,14,15}$. Here, we provide details of the purification and oligonucleotide labeling of motors from yeast ${ }^{7,16,17,18,19,20}$, the folding and purification of segmented DNA origami with tunable compliance ${ }^{8}$, and the imaging of the yeast motors propelling the chassis structures ${ }^{7,18}$.

Constructing motor ensembles for in vitro single molecule observation requires three primary efforts. The first is the expression, purification and labeling of motor constructs suitable for attaching to DNA origami. The second is the production and purification of defined DNA origami structures (often termed "chassis"). And the third is the conjugation of the motors to the chassis structure followed by observation using total internal reflection fluorescence (TIRF) microscopy. Here, we provide established protocols for this process for recombinant microtubule-based motors purified from the yeast Saccharomyces cerevisiae $7,16,17,18,19$. DNA origami-based motor ensembles have been investigated using both recombinant kinesin ${ }^{15}$ and dynein ${ }^{7,8,18}$ constructs produced in this yeast expression system ${ }^{16,17,18,19}$. This protocol is valid for these constructs, given that they are controlled by the galactose induced promoter, and fused to the same protein tags for purification (ZZ and TEV protease linker) and for DNA oligo conjugation (SNAPtag)

Specific yeast strains produce specific motor constructs. For example, the dynein used to study the role of cargo compliance was purified from strain RPY $1084^{7,8}$. In general, strains containing motor constructs with the appropriate genetic modifications for expression and purification can be requested from the laboratories having published the use of those motors. Constructs with novel attributes such as mutations or tags can be made using recombinant genetic techniques, such as lithium acetate transformation ${ }^{21}$ and commercial kits. Detailed protocols for creating modified motor proteins in yeast for single molecule studies have been published ${ }^{19}$. In addition to the motors being fused to the SNAPtag, the oligos used to label the motors must be conjugated to the SNAP substrate, benzylguanine (BG); previously published protocols 
describe the formation and purification of BG-oligo conjugates ${ }^{18}$. The overall strategy described here has also been employed for actin-based motors (see previous works for examples ${ }^{22,23,24}$ ), and motors purified from other organisms and expression systems (see previous works for examples $7,9,10,11,12,13,14$ ).

Polymerized microtubules (MTs) are used in these experiments in two different procedures. MT affinity purification of functional motors requires MTs that are not labelled with other functional groups, while the motor-ensemble motility TIRF assay requires MTs labeled with biotin and fluorophores. In all cases, MTs are stabilized with taxol to prevent denaturation. The MT affinity purification step is used to remove any non-motile motors with a high MT affinity, as these motors can alter ensemble motility if conjugated to a chassis. During this process, active motors unbind the MTs and remain in solution, while tight-binding motors spin down in the MT pellet. This helps ensure all motors on the chassis are from an active population.

A variety of DNA origami structures have been used to study cytoskeletal motor ensembles. As the mechanistic understanding of ensemble transport has increased, the DNA origami structures employed in experiments have grown in complexity. In principle, any structure could be adapted for this purpose provided it is modified to include single-stranded DNA attachment sites for motors and fluorophores. Specific chassis designs and attributes may be useful for probing particular questions about the emergent behavior of motors ensembles. For example, rigid rods have been used to develop foundational knowledge of how copy number affects transport by teams of dyneins and kinesins $s^{7,15,18}$, and $2 \mathrm{D}$ platforms have been used to study myosin ensemble navigation of actin networks ${ }^{22}$. Structures with variable or tunable flexibility have been used to understand the roles of elastic coupling between motors and to probe how stepping synchronization affects motility ${ }^{8,24}$. More recently, spherical structures are being used to gain insight into how geometrical constraints to motor-track binding affect the dynamics of motility ${ }^{25}$.

In this protocol, we offer specific steps for ensemble experiments on segmented chassis with variable rigidity. Binding sites on the chassis are sometimes referred to as "handles", while complementary DNA sequences that bind these handles are termed "antihandles". The number of motors on these chassis is determined by which segments contain extended handle staples with complementarity to the antihandle oligo on the oligo-labeled motors. Using different handle sequences on different segments allows for binding of different types of motors to specific locations on the chassis. The chassis detailed here is composed of 7 sequential rigid segments, each comprised of 12 double-stranded DNA helices arranged in 2 concentric rings ${ }^{8}$. The rigid segments contain the motor handles and are connected through regions that can be either flexible single-stranded DNA or rigid double-stranded DNA, depending on the absence or presence, respectively, of "linker" staples. The compliance of the chassis structure is thus determined by the presence or absence of these "linker" staples. See previous reports for further details and specific DNA sequences ${ }^{8}$. In addition, multiple methods can be used to purify chassis ${ }^{26}$. The rate-zonal glycerol gradient centrifugation method ${ }^{27}$ is described here.

\section{Growth, expression and harvesting of motor proteins controlled by a galactose induced promoter}

1. Using a yeast-peptone-dextrose (YPD) culture plate and a sterile inoculating stick, streak desired frozen yeast strain and incubate for 3-4 days at $30^{\circ} \mathrm{C}$.

2. Day 1 of culture growth: In the afternoon, add $10 \mathrm{~mL}$ of YP culture media with $2 \%$ dextrose to a 1 " diameter glass culture tube and inoculate it with a single colony from the plate. Grow in a rapidly rotating roller drum at $30^{\circ} \mathrm{C}$ overnight.

3. Day 2: In the afternoon, transfer the $10 \mathrm{~mL}$ of culture to a $250 \mathrm{~mL}$ flask containing $50 \mathrm{~mL}$ of YP culture media with $2 \%$ raffinose. Incubate overnight at $30^{\circ} \mathrm{C}$ while shaking at $250 \mathrm{rpm}$ on an orbital shaker.

4. Day 3: In the afternoon, transfer the $60 \mathrm{~mL}$ of culture to a $3 \mathrm{~L}$ flask containing $1 \mathrm{~L}$ of $\mathrm{YP}$ culture media with $2 \%$ galactose. Incubate overnight at $30^{\circ} \mathrm{C}$ while shaking at $250 \mathrm{rpm}$ on an orbital shaker.

5. Day 4: Starting in the mid-morning, monitor the optical density (OD) of the culture at $600 \mathrm{~nm}$ every $2 \mathrm{~h}$. When the culture is between an OD 1.5 and 2, continue with the following steps to harvest the cells. Harvesting outside of this OD range may reduce yield due to low cell counts before OD 1.5, or cellular quiescence and protein degradation above OD 2.

6. Decant the cell culture into centrifuge bottles and spin at $\sim 6200 \times g$ at $4{ }^{\circ} \mathrm{C}$ for $8 \mathrm{~min}$. Pour off the supernatant and discard.

7. Resuspend the cell pellet in the bottle with double-distilled $\mathrm{H}_{2} \mathrm{O}\left(\mathrm{ddH}_{2} \mathrm{O}\right)$.

8. Spin the cells at $\sim 6200 \times g$ at $4{ }^{\circ} \mathrm{C}$ for $8 \mathrm{~min}$. Pour off the supernatant and discard.

9. Depending on the viscosity of the cell pellet, add up to $2 \mathrm{~mL}$ of $\mathrm{dd}_{2} \mathrm{O}$ to create a solution fluid enough for pipetting.

10. Using a motorized pipette controller fitted with a $10 \mathrm{~mL}$ pipette, slowly dispense the cell slurry into liquid nitrogen one drop at a time. This will produce frozen pellets of yeast cells.

11. Store the frozen cells at $-80^{\circ} \mathrm{C}$ until ready to purify.

\section{Purification of motor proteins from yeast cells}

1. Cell lysis and soluble protein extraction

1. Prepare $1 \mathrm{~mL}$ of a fresh solution of $0.1 \mathrm{M} \mathrm{PMSF}$ in pure ethanol. Wait to add the PMSF to aqueous buffers as it is unstable in water; also, avoid exposure to water until within $20 \mathrm{~min}$ (the approximate half-life of PMSF in water) of use.

2. Prepare $50 \mathrm{~mL}$ of $4 \mathrm{x}$ lysis buffer on ice with supplements from the $5 \mathrm{x}$ stock of lysis buffer, but do not add PMSF until just before the buffer is applied to the yeast pellet.

3. Grind the liquid nitrogen-frozen yeast pellets into a fine powder with a blade-type coffee grinder that has been pre-chilled with liquid nitrogen.

NOTE: This protein extraction typically starts with the cell pellet harvested from $2 \mathrm{~L}$ of yeast culture. The starting amount of yeast culture can be adjusted up or down with commensurate adjustments to the volumes of IgG beads and DNA oligos in steps 2.2 .2 and 2.3.1 below. 
4. Aliquot $15 \mathrm{~mL}$ of the $4 \mathrm{x}$ lysis buffer with DTT and Mg-ATP on ice and add PMSF to the buffer to achieve a final concentration of $2 \mathrm{mM}$, completing the preparation of the $4 x$ lysis buffer with supplements.

5. Collect the yeast powder into a pre-chilled $\sim 100 \mathrm{~mL}$ glass beaker on ice. Add a small volume of the $4 x$ lysis buffer with supplements into the powder so that the final concentration of the buffer does not exceed $1 \mathrm{x}$. Typically, add $\sim 1.5 \mathrm{~mL}$ of the buffer for every $10 \mathrm{~mL}$ of yeast powder.

6. Quickly thaw the powder to the liquid phase by placing the beaker in a $37{ }^{\circ} \mathrm{C}$ water bath with constant stirring using a spatula.

7. Place the beaker of lysate back on ice immediately after thawing, estimate the lysate volume using a $50 \mathrm{~mL}$ conical tube, and add more $4 x$ lysis buffer with supplements so that the final concentration of the buffer is $\sim 1 x$. Typically, $2 \mathrm{~L}$ of yeast culture yields a total of $25-35$ $\mathrm{mL}$ of lysate containing $1 \mathrm{x}$ lysis buffer.

8. Evenly distribute the lysate to centrifuge bottles on ice. Carefully balance the bottles to a mass difference no more than $0.01 \mathrm{~g}$ between each pair, ensuring that each bottle is above the minimum volume required to prevent bottle collapse. Centrifuge at $\sim 290,000 \times g$ for 25 $\min$ at $4{ }^{\circ} \mathrm{C}$.

9. Collect the supernatant containing soluble proteins in a $50 \mathrm{~mL}$ conical tube on ice, and discard the pellet containing cell debris and large organelles. Avoid collecting any cloudy portions of the supernatant, as they can clog the gravity-flow column used in subsequent steps. Save $10 \mu \mathrm{L}$ of the supernatant for SDS-PAGE analysis.

\section{IgG affinity purification}

1. During the spin above, set up a gravity-flow chromatography column on ice or in a cold room.

2. Transfer $200 \mu \mathrm{L}$ of $50 \%$ lgG affinity bead slurry to the column using a P-1000 pipette tip cut with a razor blade to enlarge the diameter of its entry port. If purifying more or less than $2 \mathrm{~L}$ of cell culture pellet, adjust the volume of bead slurry proportionately, with a minimum volume of $100 \mu \mathrm{L}$

3. Aliquot another $15 \mathrm{~mL}$ of the $4 x$ lysis buffer with DTT and Mg-ATP and add PMSF to the buffer to achieve a final concentration of $2 \mathrm{mM}$. Dilute the $4 x$ buffer on ice to $1 x$ by adding $\mathrm{ddH}_{2} \mathrm{O}$.

4. Wash the beads $2 x$ with $5 \mathrm{~mL}$ of $1 x$ lysis buffer with supplements.

5. Resuspend the beads in $200 \mu \mathrm{L}$ of $1 \mathrm{x}$ lysis buffer with supplements.

6. Add the bead suspension to the protein extract obtained from centrifugation and incubate the mixture at $4{ }^{\circ} \mathrm{C}$ for $1 \mathrm{~h}$ with gentle rotation.

7. During the incubation, prepare $25 \mathrm{~mL}$ of the wash buffer (recipe detailed in Table 1) on ice and $50 \mathrm{~mL}$ of $1 \mathrm{x}$ TEV buffer (recipe detailed in Table 1) on ice.

8. After the $1 \mathrm{~h}$ incubation, filter the lysate-bead mixture on ice or in the cold room through the same chromatography column used in step 2.2.2 above. Save $10 \mu \mathrm{L}$ of the flow-through for SDS-PAGE analysis.

9. Wash the remaining motor-bound beads on ice $2 x$ with $5 \mathrm{~mL}$ of wash buffer. Save $10 \mu \mathrm{L}$ of the first wash for SDS-PAGE analysis.

10. Wash the beads on ice once with $5 \mathrm{~mL}$ of $1 x$ TEV buffer. Allow the buffer to fully drain from the column.

\section{Labeling with DNA oligonucleotides and TEV cleavage}

1. Remove the chromatography column from the setup and cap the bottom of the column. Within the same column, incubate the motorbeads with $100 \mu \mathrm{L}$ of $1 \mathrm{x}$ TEV buffer containing 10-20 $\mu \mathrm{M}$ of the purified BG-oligo at room temperature (RT) for 10-15 min. If purifying more or less than $2 \mathrm{~L}$ of cell culture pellet, adjust the volume of $1 \mathrm{x}$ TEV buffer and purified BG-oligos proportionately. Increase the incubation time according to manufacturer's instructions if needed to increase the yield and rate of motor labeling, but be aware that longer incubation times may also increase the proportion of dysfunctional motors due to protein denaturation at RT.

2. Gently resuspend the beads every minute of the incubation.

3. Wash the labeled motor-beads $4 \mathrm{x}$ with $4 \mathrm{~mL}$ of $1 \mathrm{x}$ TEV buffer using the same chromatography column and setup as before. Allow the final wash to fully drain from the column.

4. Cap the bottom of the column, resuspend the motor-beads in no more than $200 \mu \mathrm{L}$ of $1 \times$ TEV Buffer, and transfer to a $2 \mathrm{~mL}$ roundbottom microcentrifuge tube.

5. Incubate the suspension with $\sim 0.3$ units of TEV protease per $\mu \mathrm{L}$ of motor-bead mixture at $16{ }^{\circ} \mathrm{C}$ for $1 \mathrm{~h}$ with gentle rotations. The tube should be mounted so as to minimize the total surface area of the tube with which the beads come into contact.

6. Centrifuge the tube in a microcentrifuge at $21,130 \times \mathrm{g}$ for $30 \mathrm{~s}$ in a cold room to concentrate the mixture at the bottom of the tube.

7. Still in the cold room, use a cut $\mathrm{P}-1000$ pipette tip to transfer the mixture to a spin column and centrifuge at $21,130 \times \mathrm{g}$ for $30 \mathrm{~s}$. Collect the filtrate containing the TEV-cleaved, purified motors. The TEV protease will be in the filtrate as well as the motors.

8. Save $10 \mu \mathrm{L}$ of the filtrate for SDS-PAGE analysis. Aliquot the remaining filtrate in volumes of $2 \mu \mathrm{L}$ for TIRF experiments or $50 \mu \mathrm{L}$ for microtubule affinity purification. Flash freeze the aliquots in liquid nitrogen and store at $-80^{\circ} \mathrm{C}$.

9. Resuspend the beads remaining in the filter in 1x TEV buffer for SDS-PAGE analysis. Use the same volume of $1 x$ TEV buffer as in step 2.3.4 above.

\section{Microtubule (MT) polymerization}

\section{Preparation of tubulin mixes for TIRF assays}

1. In a cold room, separately dissolve the lyophilized tubulin of each type (unlabeled bovine tubulin, biotinylated tubulin, and fluorescent tubulin) in reconstitution buffer (recipe detailed in Table 2) to make a final concentration of $10 \mathrm{mg} / \mathrm{mL}$. Let sit on ice for $10 \mathrm{~min}$.

1. Mix the following components and let sit on ice for $10 \mathrm{~min}$ in the cold room (final concentrations are indicated parenthetically): 18 $\mu \mathrm{L}$ of bovine tubulin $(\sim 8.2 \mathrm{mg} / \mathrm{mL}), 2 \mu \mathrm{L}$ of biotinylated tubulin $(\sim 0.9 \mathrm{mg} / \mathrm{mL})$, and $2 \mu \mathrm{L}$ of fluorescent tubulin $(\sim 0.9 \mathrm{mg} / \mathrm{mL})$.

2. Prepare $3 \mu \mathrm{L}$ aliquots of the tubulin mixture and flash freeze in liquid nitrogen. Store the mixtures at $-80^{\circ} \mathrm{C}$.

\section{Preparation of tubulin for MT affinity purification of motors}

1. In a cold room, dissolve lyophilized bovine tubulin in the reconstitution buffer to make a final concentration of $10 \mathrm{mg} / \mathrm{mL}$. Let sit on ice for $10 \mathrm{~min}$. 
2. Prepare $3 \mu \mathrm{L}$ aliquots of the tubulin mixture and flash freeze in liquid nitrogen. Store the mixtures at $-80^{\circ} \mathrm{C}$.

\section{Polymerization of tubulin into MTs}

1. Remove a $3 \mu \mathrm{L}$ aliquot of tubulin from the $-80^{\circ} \mathrm{C}$ freezer and very quickly and briefly thaw to the liquid phase by holding the bottom of the tube. Immediately place on ice and incubate for at least 3 min.

2. Gently layer $3 \mu \mathrm{L}$ of $2 x$ polymerization mix (recipe detailed in Table 2) on top of the tubulin solution. Mix by gently flicking the tube, but do not mix by pipetting, as shear forces may disrupt MT nucleation and elongation.

3. Incubate the mixture in a water bath at $37^{\circ} \mathrm{C}$ for $30 \mathrm{~min}$.

4. Gently layer $6 \mu \mathrm{L}$ of RT $1 \times$ BRB80 with supplements (recipe detailed in Table 2) on top and mix by flicking. Do not mix by pipetting.

5. Incubate the mixture at $37^{\circ} \mathrm{C}$ for at least $10 \mathrm{~min}$.

6. Proceed to MT affinity purification, or if doing TIRF assays, incubate MTs in the dark at RT overnight to form longer MTs.

7. Store polymerized MTs for weeks in the dark at RT.

\section{Microtubule (MT) affinity purification}

\section{Removal of unpolymerized tubulins by centrifugation}

1. Mix the following components to make a $60 \%$ glycerol cushion: 1x BRB80 (without supplements; recipe detailed in Table 2), $20 \mu \mathrm{M}$ Taxol (dissolved in DMSO), $1 \mathrm{mM}$ DTT, and 60\% glycerol.

2. Transfer $60 \mu \mathrm{L}$ of the glycerol cushion to an ultracentrifuge tube. Gently layer $12 \mu \mathrm{L}$ of the unlabeled MTs polymerized previously on top of the cushion. To prevent shearing of MTs, transfer them using a cut pipette tip.

3. Centrifuge the mixture at $\sim 97,300 \times g$ at $22^{\circ} \mathrm{C}$ for $15 \mathrm{~min}$. After the spin, the excess tubulins remain in the top liquid layer, while the MTs form a pellet at the bottom. Mark the outer edge of the tube before the spin to help locate the pellet, as the pellet may not be visible with the naked eye.

4. Carefully remove the liquid layer $(\sim 12 \mu \mathrm{L})$ above the glycerol cushion and save $10 \mu \mathrm{L}$ for SDS-PAGE analysis.

5. Gently rinse the interface between the liquid layer and cushion with $20 \mu \mathrm{L}$ of $1 \times$ BRB80 with supplements. Remove and discard the 20 $\mu \mathrm{L}$ rinse.

6. Carefully remove the glycerol cushion $(\sim 60 \mu \mathrm{L})$ and save $10 \mu \mathrm{L}$ for SDS-PAGE analysis. Be careful not to disturb the MT pellet.

7. Gently rinse the pellet with $60 \mu \mathrm{L}$ of $1 \times$ BRB80 with supplements (recipe detailed in Table 2). Be careful not to disturb the MT pellet. Discard the rinse solution.

8. Resuspend the MT pellet in $24 \mu \mathrm{L}$ of Taxol-supplemented lysis buffer (recipe detailed in Table 3 ) using a cut pipette tip.

\section{Purification of functional motors by MT-based affinity chromatography}

1. Remove two $50 \mu \mathrm{L}$ aliquots of motors purified from yeast from the $-80 \mathrm{C}$ freezer and quickly thaw to the liquid phase. Immediately place on ice.

2. Add the following components to a new ultracentrifuge tube in the indicated order and incubate the mixture at RT for $10 \mathrm{~min}$ : (1) $100 \mu \mathrm{L}$ of the motors purified from yeast, (2) $29 \mu \mathrm{L}$ of $5 x$ ATP/Taxol mix (recipe detailed in Table 3), then (3) $12 \mu \mathrm{L}$ of purified MTs transferred with a cut pipette tip.

3. Centrifuge the mixture at $\sim 97,300 \times g$ and $22^{\circ} \mathrm{C}$ for $15 \mathrm{~min}$. After the spin, functional motors remain in the supernatant, and MTs form a pellet, along with the non-functional motors bound to them.

4. Collect the supernatant, flash freeze in $2 \mu \mathrm{L}$ aliquots, and store at $-80^{\circ} \mathrm{C}$.

5. Save $10 \mu \mathrm{L}$ of the supernatant for SDS-PAGE analysis. Resuspend the pellet in $141 \mu \mathrm{L}$ of $1 \times$ BRB80 for SDS-PAGE analysis, too. Use protein standards, such as actin, to create a standard curve for quantifying the concentration of the purified motors as previously detailed $^{17}$.

6. Use this concentration information when conjugating motors to the chassis in step 6.1.3.

\section{Production of segmented DNA origami chassis}

\section{Formation of chassis}

1. Order the staple oligonucleotides listed in previously published tables ${ }^{8}$ in 96 well plates wet at $250 \mu \mathrm{M}$ in Tris buffer, or dry and then resuspend them to $250 \mu \mathrm{M}$ with Tris buffer.

2. Create a pool of the core staples by mixing $5 \mu \mathrm{L}$ of each core staple (see table $\mathrm{S} 1$ in Driller-Colangelo $2016^{8}$ ).

3. Create a pool of the linker staples by mixing $5 \mu \mathrm{L}$ of each linker staple (see linker staple table in Driller-Colangelo $2016^{8}$ ).

4. Create a pool of the fluorophore binding staples by mixing $5 \mu \mathrm{L}$ of each fluorophore handle staple (see fluorophore handle table in Driller-Colangelo $2016^{8}$ ).

5. Mix $50 \mu \mathrm{L}$ folding reactions with the following components: 1x Folding buffer; $100 \mathrm{nM} 8064$ scaffold; $600 \mathrm{nM}$ core staple pool; $600 \mathrm{nM}$ fluorophore staple pool; $9 \mu \mathrm{M}$ fluorophore strand (see fluorophore antihandle table in Driller-Colangelo $2016^{8}$ ); for each motor binding site, either $4.2 \mu \mathrm{M}$ extended handle strands or $600 \mathrm{nM}$ strands without handles as desired (see motor handle/antihandle staples table in Driller-Colangelo $\left.2016^{8}\right) ; 600 \mathrm{nM}$ linkers as desired ${ }^{8}$; additional $6 \mathrm{mM} \mathrm{MgCl}_{2}$; and water.

6. Fold in a thermal cycler using the following program: Rapid heating to $80^{\circ} \mathrm{C}$, cooling in single degree increments to $65{ }^{\circ} \mathrm{C}$ over 75 min, then additional cooling in single degree increments to $30^{\circ} \mathrm{C}$ over $17.5 \mathrm{~h}$.

7. Assay folding quality on a $2 \%$ agarose gel in $0.5 x$ TBE buffer (see Table 4 for recipe) supplemented with $11 \mathrm{mM} \mathrm{MgCl} 2$ and DNA gel stain (see Table of Materials). Run gel in $0.5 x$ TBE buffer supplemented with $11 \mathrm{mM} \mathrm{MgCl}_{2}$ at $70 \mathrm{~V}$ for $60-90$ min. Run gels in an ice water bath or in a cold room to prevent excessive heating and subsequent denaturation of chassis structures.

8. Image the gel using conditions suitable for the DNA gel stain used in step 5.1.7.

\section{Purification of chassis}


1. In the late afternoon the day before purification, create glycerol gradients by gently layering $80 \mu \mathrm{L}$ each of $45 \%, 40 \%, 35 \%, 30 \%, 25 \%$, $20 \%$, and $15 \%$ glycerol in $1 \mathrm{x}$ origami folding buffer in a centrifuge tube (see Table 4 for recipe). Boundaries between layers should be slightly visible.

2. Incubate gradients at $4{ }^{\circ} \mathrm{C}$ overnight.

3. The next morning, add $45 \%$ glycerol in $1 x$ origami folding buffer to the folded chassis solution to a final concentration of $10 \%$ glycerol. Mix gently and layer on the top of the gradient in the centrifuge tube.

4. Spin the gradient with the chassis at $243,000 \times g$ for $130 \mathrm{~min}$ at $4{ }^{\circ} \mathrm{C}$

5. Collect $50 \mu \mathrm{L}$ fractions from the tube in a top to bottom direction.

6. Cast a $2 \%$ agarose gel in $0.5 \times \mathrm{TBE}$ buffer supplemented with $11 \mathrm{mM} \mathrm{MgCl}$ and DNA gel stain.

7. Load $5 \mu \mathrm{L}$ of each fraction on the gel and run gel in $0.5 x$ TBE buffer supplemented with $11 \mathrm{mM} \mathrm{MgCl}_{2}$ for $90-120$ min at $70 \mathrm{~V}$. Run gels in an ice water bath or in a cold room to prevent excessive heating and subsequent denaturation of chassis structures.

8. Image the gel using conditions suitable for the DNA gel stain used in step 5.2.6.

9. Select fractions for future experiments that exhibit well-folded monomeric structures free of unincorporated staples.

10. Quantified concentrations of selected fractions using appropriate spectroscopic methods, such as UV absorption at $260 \mathrm{~nm}$. Use this concentration information when conjugating motors to the chassis in step 6.1.3.

\section{Making slide assay chambers}

1. Make a slide assay chamber by sticking two strips of double-sided tape to a glass slide and placing a coverslip on top. The chamber is the narrow space sandwiched between the coverslip and glass slide, flanked by the two strips of tape. Figure 1 illustrates the assay chamber.

2. When preparing the slide with solutions, use a pipette to flow any fluid into the chamber from one side, and use a strip of filter paper to collect the flow of the fluid on the other side.

\section{Motor-ensemble motility TIRF assay}

\section{Conjugation of motors to DNA chassis}

1. On ice, prepare fresh $1 \mathrm{~mL}$ each of DTT-supplemented BRB80, Taxol-supplemented lysis buffer, and casein-Taxol-supplemented lysis buffer (recipes detailed in Table 5). Transfer $200 \mu \mathrm{L}$ of each buffer to a RT tube.

2. Still on ice, use the cold casein-Taxol-supplemented lysis buffer to prepare the $4 x$ energy and $4 x$ scavenger mixes (recipes detailed in Table 5).

3. Incubate $10 \mu \mathrm{L}$ of $\sim 300 \mathrm{nM}$ purified motors with $5 \mu \mathrm{L}$ of $\sim 10 \mathrm{nM}$ DNA chassis on ice for $15-30$ min. These concentrations of motors have been shown to saturate the chassis' motor binding sites for this incubation time. NOTE: motor occupancy is not $100 \%$, likely due to stochastically missing handle staples in individual chassis structures ${ }^{8,28}$.

4. During the incubation, dilute the biotin- and fluorophore-labeled MTs 100x with the RT Taxol-supplemented lysis buffer, and prepare a gel filtration resin appropriate for size exclusion column chromatography by following the procedure outlined below.

2. Removal of excess motors from motor-chassis conjugates by size exclusion column chromatography

1. In a $50 \mathrm{~mL}$ conical tube, wash $5 \mathrm{~mL}$ of the gel filtration resin $2 x$ with $45 \mathrm{~mL}$ of ddH $\mathrm{H}_{2} \mathrm{O}$. For each wash, mix the resin with water in the conical tube, and spin the mixture at $460 \times g$ for $1 \mathrm{~min}$. Discard the supernatant and save the resin.

2. Wash the resin $2 x$ with $45 \mathrm{~mL}$ of $1 x$ lysis buffer (recipe detailed in Table 5) using the same method described above.

3. Resuspend the washed resin in $1 x$ lysis buffer in a $1: 1$ ratio, so that the resin becomes a $~ 50 \%$ slurry in buffer. The washed resin can be stored at $4{ }^{\circ} \mathrm{C}$ for at least 1 month.

4. Transfer $800 \mu \mathrm{L}$ of the resin suspension to a spin column. Drain the excess buffer by gravity flow for 5 min. Remove any remaining buffer with a $2 \mathrm{~s}$ spin at $1,000 \times \mathrm{g}$. The final resin volume should be around $350-400 \mu \mathrm{L}$.

5. Dilute the motor-chassis mix with the casein-Taxol-supplemented lysis buffer to a final volume of $50 \mu \mathrm{L}$. Transfer the diluted mix to the spin column packed with resin.

6. Centrifuge the spin column at $1,000 \times g$ for $6 \mathrm{~s}$ (this time is inclusive of the acceleration and deceleration time). Collect the pure motorchassis conjugates by saving the filtrate and discard the column which retains the excess motors.

\section{Preparation of slides for imaging}

1. Flow $13 \mu \mathrm{L}$ of $1 \mathrm{mg} / \mathrm{mL}$ biotinylated bovine serum albumin (biotin-BSA) into a slide assay chamber. Incubate for 2 min to allow binding of BSA to glass.

2. Wash the chamber $2 x$ with $20 \mu \mathrm{L}$ of the RT DTT-supplemented BRB80 by flowing in the buffer on one side of the chamber and wicking the excess fluid away from the other side using a strip of filter paper.

3. Flow in $20 \mu \mathrm{L}$ of $0.5 \mathrm{mg} / \mathrm{mL}$ streptavidin. Incubate for $2 \mathrm{~min}$ to allow binding of streptavidin to the biotin on the BSA.

4. Wash the chamber $2 x$ with $20 \mu \mathrm{L}$ of the RT Taxol-supplemented lysis buffer.

5. Gently flow in $20 \mu \mathrm{L}$ of the diluted MTs with a cut pipette tip. Incubate for 2 min to allow binding between the biotin on MTs and streptavidin.

6. Wash $2 x$ with $20 \mu \mathrm{L}$ of the RT casein-Taxol-supplemented lysis buffer. Incubate for 2 min to allow casein to permeate the entire chamber.

7. Dilute the purified motor-chassis conjugates $5 x$ to $10 x$ to single-molecule conditions $(\sim 10-100 \mathrm{pM})$ with the cold casein-Taxolsupplemented lysis buffer. Mix together the following components to produce a final motor-chassis mixture: $10 \mu \mathrm{L}$ of the motor-chassis dilution, $5 \mu \mathrm{L}$ of $4 \mathrm{x}$ energy mix, and $5 \mu \mathrm{L}$ of $4 \mathrm{x}$ scavenger mix.

8. Flow in $20 \mu \mathrm{L}$ of the final motor-chassis mixture to the assay slide chamber and proceed to TIRF microscopy.

\section{Imaging and data acquisition}

1. Image the slide immediately with a TIRF microscope. Typically, each slide remains useable for between 30 and $60 \mathrm{~min}$. 
2. Acquire a still image in the MT channel, and a movie in the chassis channel. For the motors in this protocol, 10 min movies with a frame rate of $0.5 \mathrm{fps}$ and exposure time of $200 \mathrm{~ms}$ are appropriate.

3. From the chassis movie, generate one kymograph for each MT in Image J or a similar image processing software ${ }^{29}$. Analyze the velocities and run lengths of motor-chassis ensembles by measuring the slopes and horizontal distances of the runs on the kymograph $^{30}$.

\section{Representative Results}

Successful purifications of motors and chassis structures were assayed by gel electrophoresis. SDS-PAGE analysis confirmed the successful extraction of dynein from yeast (Figure 2), as the final filtrate collected in step 2.3.7 showed a clear, sharp band at the position of $\sim 350 \mathrm{kDa}$. As expected, this dynein band was absent from the flowthrough and wash that removed unwanted proteins, and the beads from which dynein was cleaved. The observation suggests that the IgG affinity purification and TEV protease cleavage were both highly efficient. Additionally, TEV protease was also present in the final filtrate and formed a clear band at $\sim 50 \mathrm{kDa}$.

The successful MT affinity purification of dynein and kinesin proteins was also confirmed with SDS-PAGE analysis (Figure 3). While dynein showed up as a clear single band at $\sim 350 \mathrm{kDa}$, kinesin showed up as slightly smearing multiple bands at $\sim 120 \mathrm{kDa}$, possibly due to the presence of both phosphorylated and dephosphorylated forms of the protein ${ }^{14}$ and variable yields in oligo-labeling. A comparison between the dynein and kinesin bands before and after this MT affinity purification revealed a reduction in the motor concentration, as indicated by the decrease in the band intensity, which was likely due to the removal of non-functional motors. Despite the reduction, the concentrations of motors retained were sufficient for effective TIRF assays. In addition to the TEV protease, a noticeable amount of tubulin ( $51 \mathrm{kDa})$ was present in the final supernatant, most likely due to the gradual decomposition of MTs during the experiment, or incomplete removal of the excess tubulin through centrifugation. However, the consistent motility of motor-chassis ensembles shown in TIRF assays suggests that tubulin and TEV protease did not interfere with motor functions (see Figure 6).

Folding of DNA origami structures was assayed by agarose gel electrophoresis. Figure 4 depicts the results of a gel analyzing the folding of a flexible segmented chassis with 2 motor binding sites. The shift in mobility between the pure unfolded scaffold strand (Lane 1) and the folding reaction (Lane 2) indicates origami folding. Additionally, the folding reaction in Lane 2 indicates the presence of some multimerization of chassis structures. Multimerization typically occurs, and requires subsequent purification of the well-folded monomeric structures. The unincorporated excess staples were also visible, displaying a high degree of mobility through the gel.

Folded origami reactions were purified to remove excess unincorporated staples and multimers of the chassis structure. Figure 5 shows the results of a glycerol gradient purification of a flexible chassis with 7 motor binding sites. The early fractions correspond to the low glycerol density at the top of the tube. They contain the excess staples. The late fractions correspond to the high glycerol densities at the bottom of the tube and contain multimers and aggregates of folded structures. In this gel, fraction 7 indicates a suitable fraction containing well-folded monomeric chassis. Note that the well-folded structure is isolated from both excess staples and multimers. While this gel is representative, and fraction 7 often contains useable chassis, each purification experiment yields slightly different results and fractions should always be assayed to determine which fraction is best for motility assays.

The motility of motor-chassis ensembles is easily detectable and measurable on the kymographs generated from TIRF movies. For instance, the kymographs (Figure 6) of flexible chassis conjugated to seven dynein proteins ("7D" ensembles) show highly processive runs at relatively consistent velocities, demonstrating that the ensembles were active and motile in the reconstituted system, and that MT affinity purification successfully removed most of the non-functional, immobile dyneins that could slow or stall the ensembles. The same TIRF experiment has been successfully performed on other chassis types with different compliance and motor numbers to reveal the effects of these factors on dynein teamwork ${ }^{8,9}$.

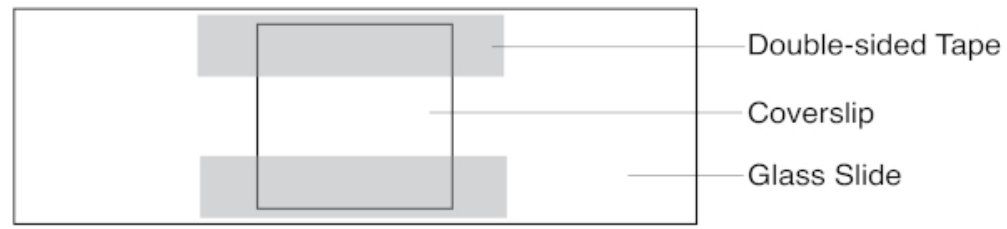

Figure 1: Schematic of the slide assay chamber. The coverslip sits atop two strips of double-sided tape. Solutions are pipetted in one side, and extracted with filter paper on the other. Please click here to view a larger version of this figure. 


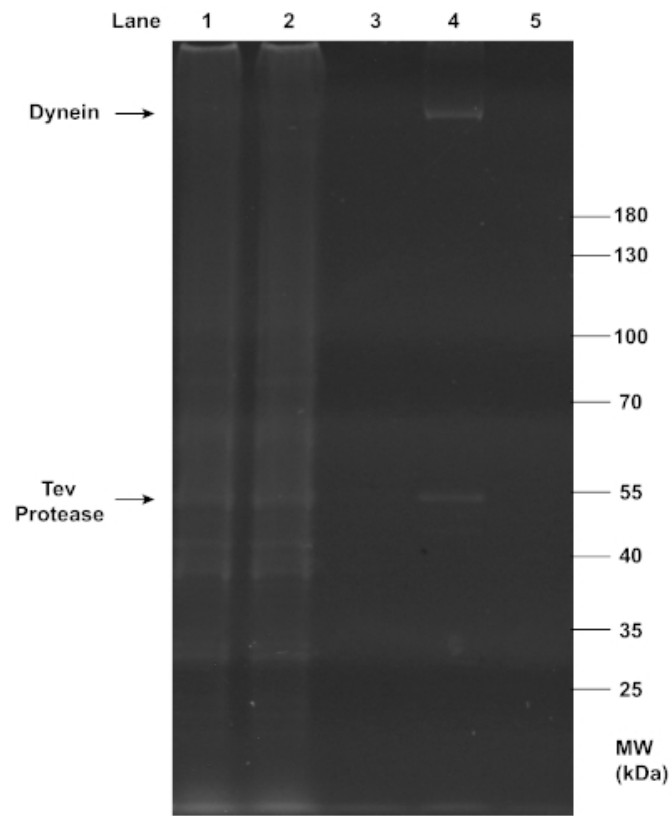

Figure 2: SDS-PAGE analysis of the purification of dynein from yeast. Yeast cells were lysed and centrifuged to collect the lysate (lane 1) containing total soluble proteins. The affinity between IgG on column beads and the $Z Z$ tag on the recombinant dynein construct was exploited for this purification. The flow-through (lane 2) was collected from the mixture of the lysate and beads after it passed through a chromatography column. The dynein-bound beads were washed with buffers, and the first wash with the wash buffer (lane 3 ) was collected. Dynein was then conjugated to a DNA oligo. After TEV protease cleavage, centrifugation in a spin column separated the filtrate containing dynein (lane 4) and the residual beads (lane 5). All samples collected from the purification were denatured with 1x LDS Sample Buffer and 1x Reducing Agent, and loaded onto a $4-12 \%$ Bis-Tris gel. The gel was run in 1x MOPS buffer at $200 \mathrm{~V}$ for $\sim 1 \mathrm{~h}$, and stained with SYPRO Red Protein Gel Stain for imaging under UV light. Notably, the clear, sharp band at $\sim 350 \mathrm{kDa}$ in lane 4 indicates the presence of concentrated purified dynein in the final filtrate, while the band at $\sim 50 \mathrm{kDa}$ in the same lane indicates the co-presence of TEV protease. Please click here to view a larger version of this figure.

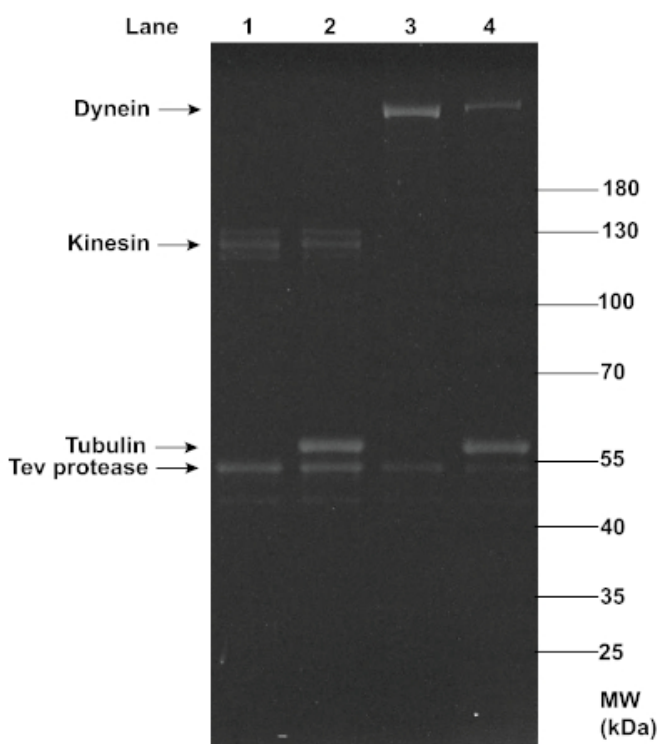

Figure 3: SDS-PAGE analysis of the MT affinity purification of functional dynein and kinesin proteins. Kinesin and dynein purified from yeast (lanes 1 and 3 ) were mixed with polymerized MTs and ATP, and ultracentrifugation was performed to separate the functional motors in the supernatants (lanes 2 and 4) from the non-functional motors that co-pellet with MTs. The motor samples before and after purification were denatured with 1x LDS Sample Buffer and 1x Reducing Agent, and loaded onto a 4-12\% Bis-Tris gel. The gel was run in 1x MOPS buffer at 200 $\mathrm{V}$ for $\sim 1 \mathrm{~h}$, and stained with SYPRO Red Protein Gel Stain for imaging under UV light. The intensity of the motor bands ( 120 kDa for kinesin, and $\sim 350 \mathrm{kDa}$ for dynein) appeared to decrease after the MT affinity purification, indicating a reduction in the motor concentrations. Noticeable concentrations of tubulin and TEV protease were present in the post-purification motor samples. Please click here to view a larger version of this figure. 


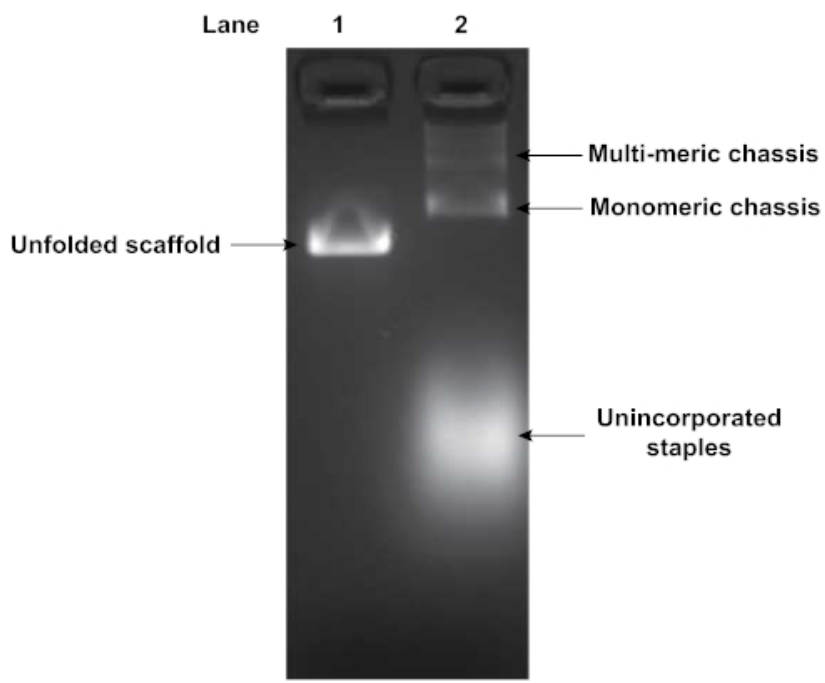

Figure 4: Agarose gel analysis of folded DNA origami structure. Folded DNA origami structures are assessed by gel electrophoresis. Lane 1 is the pure unfolded scaffold strand while lane 2 is the product of the folding reaction. Gel was run at $70 \mathrm{~V}$ in an ice water bath for 90 min in $0.5 \mathrm{x}$ TBE buffer supplemented with $11 \mathrm{mM} \mathrm{MgCl}_{2}$. A shift in mobility indicates origami folding. Unincorporated staples and chassis multimers were also visible in Lane 2. Please click here to view a larger version of this figure.

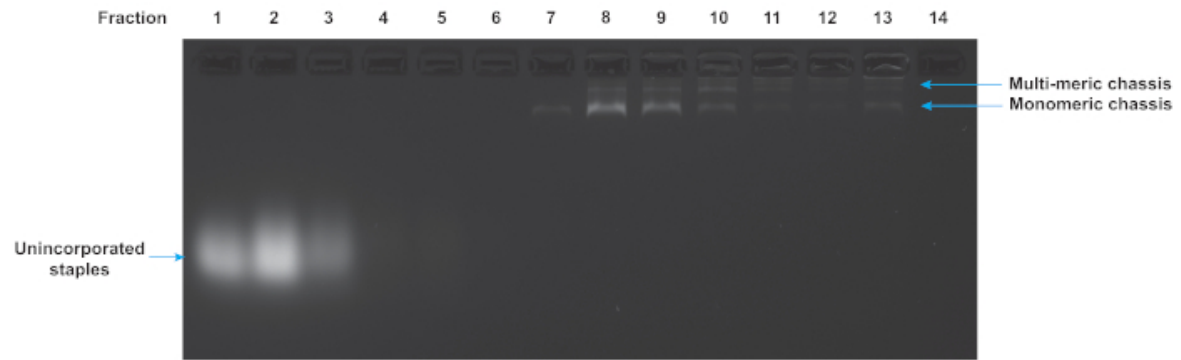

Figure 5: Agarose gel analysis of glycerol gradient purification of DNA origami chassis. The quality of the glycerol gradient purification can be determined by gel electrophoresis of the fractions from the centrifuge gradient. Low number fractions are from the top of the tube and correspond to low density of glycerol. High numbered fractions are from the bottom of the tube and correspond to high densities of glycerol. The excess staples, monomeric chassis, and multimeric chassis are all visible. Fraction 7 contains chassis suitable for TIRF microscopy as they are monomeric and excess staples are absent. Gel was run at $70 \mathrm{~V}$ in an ice water bath for $120 \mathrm{~min}$ in $0.5 \mathrm{x}$ TBE buffer supplemented with $11 \mathrm{mM}$ $\mathrm{MgCl}_{2}$. Please click here to view a larger version of this figure.

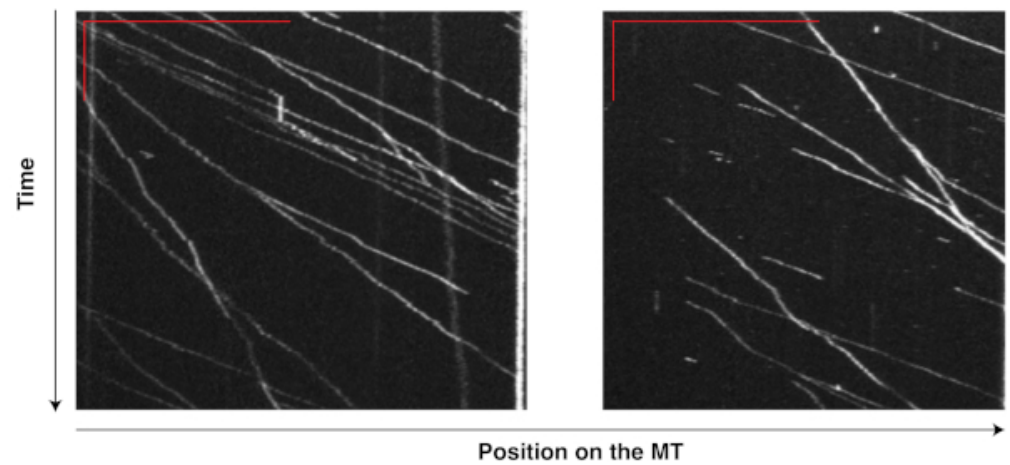

Figure 6: Kymographs showing the motility of dynein-chassis ensembles on single MTs. Dynein proteins extracted from yeast and purified with MTs were conjugated to flexible chassis structures. Each chassis had seven binding sites for dynein and formed a "7D" ensemble. The movement of these ensembles on MTs was recorded in a $10 \mathrm{~min}$ movie (200 ms exposure, $0.5 \mathrm{fps}$ ) during a TIRF assay. Kymographs from two MTs were generated from this movie in ImageJ by tracing along a single MT. The vertical and horizontal red bars in the top left corner of each image indicate $2 \mathrm{~min}$ and $20 \mu \mathrm{m}$, respectively. Each bright line records the movement of one ensemble, with the inverse of the slope indicating the velocity and horizontal displacement indicating the run length. With TIRF assays and kymography, the motility of motor-chassis ensembles becomes easily detectable and directly measurable. Please click here to view a larger version of this figure. 


\begin{tabular}{|c|c|c|c|}
\hline Buffer Name & Composition & Step(s) Used & Comment \\
\hline \multirow[t]{5}{*}{ 5x Lysis Buffer } & 150 mM HEPES (pH 7.4) & \multirow[t]{5}{*}{-} & \multirow{5}{*}{$\begin{array}{l}\text { Filter sterilize the buffer. It can be } \\
\text { stored at RT in a properly sealed } \\
\text { container for a year. }\end{array}$} \\
\hline & 250 mM KAcetate & & \\
\hline & $10 \mathrm{mM}$ MgAcetate & & \\
\hline & 5 mM EGTA (pH 7.5) & & \\
\hline & $50 \%$ glycerol & & \\
\hline \multirow{4}{*}{$\begin{array}{l}\text { 4x Lysis Buffer With } \\
\text { Supplements }\end{array}$} & $4 x$ Lysis Buffer & \multirow[t]{4}{*}{$2.1-2.2$} & \multirow{4}{*}{$\begin{array}{l}\text { Make this } 4 x \text { buffer from the } 5 x \\
\text { lysis buffer above. Prepare a buffer } \\
\text { without PMSF first, and add the } \\
\text { compound (dissolved in pure } \\
\text { ethanol) to a small aliquot of the } \\
\text { buffer right before each step that } \\
\text { requires it. }\end{array}$} \\
\hline & $4 \mathrm{mM} \mathrm{DTT}$ & & \\
\hline & $0.4 \mathrm{mM}$ Mg-ATP & & \\
\hline & $2 \mathrm{mM}$ PMSF & & \\
\hline \multirow[t]{3}{*}{ Wash Buffer } & 1x Lysis Buffer With Supplements & \multirow[t]{3}{*}{2.2} & \multirow{3}{*}{$\begin{array}{l}\text { To make the buffer, add } \mathrm{KCl} \text {, Triton } \\
\mathrm{X}-100 \text {, and } \mathrm{ddH}_{2} \mathrm{O} \text { to the } 4 \mathrm{x} \text { lysis } \\
\text { buffer with DTT and Mg-ATP, but } \\
\text { do not add PMSF until right before } \\
\text { use. }\end{array}$} \\
\hline & $250 \mathrm{mM} \mathrm{KCl}$ & & \\
\hline & $0.1 \%$ Triton $\mathrm{X}-100$ & & \\
\hline \multirow[t]{3}{*}{ 5x TEV Buffer } & $50 \mathrm{mM}$ Tris- $\mathrm{HCl}(\mathrm{pH} 8.0)$ & \multirow[t]{3}{*}{-} & \multirow{3}{*}{$\begin{array}{l}\text { Filter sterilize the buffer. It can be } \\
\text { stored at RT in a properly sealed } \\
\text { container for a year. }\end{array}$} \\
\hline & $150 \mathrm{mM} \mathrm{KCl}$ & & \\
\hline & $10 \%$ Glycerol & & \\
\hline \multirow[t]{5}{*}{ 1x TEV Buffer } & 1x TEV Buffer & \multirow[t]{5}{*}{$2.2-2.3$} & \multirow{5}{*}{$\begin{array}{l}\text { To make the buffer, add DTT, Mg- } \\
\text { ATP, Triton X-100, and ddH }{ }_{2} \mathrm{O} \text { to } \\
\text { the } 5 x \text { stock TEV buffer, but do not } \\
\text { add PMSF until right before use. }\end{array}$} \\
\hline & $1 \mathrm{mM}$ DTT & & \\
\hline & $0.1 \mathrm{mM}$ Mg-ATP & & \\
\hline & $0.1 \%$ Triton $\mathrm{X}-100$ & & \\
\hline & $0.5 \mathrm{mM}$ PMSF & & \\
\hline
\end{tabular}

Table 1: Buffers for the IgG affinity purification of motor proteins from yeast cells (Protocol section 2).

\begin{tabular}{|c|c|c|c|}
\hline Buffer Name & Composition & Step(s) Used & Comment \\
\hline \multirow[t]{4}{*}{ 5x BRB80 } & 400 mM PIPES & \multirow[t]{4}{*}{-} & \multirow{4}{*}{$\begin{array}{l}\text { Filter sterilize the buffer. It can be } \\
\text { stored at RT in a properly sealed } \\
\text { container for a year. }\end{array}$} \\
\hline & $10 \mathrm{mM} \mathrm{MgCl} 2$ & & \\
\hline & $5 \mathrm{mM}$ EGTA & & \\
\hline & Adjust $\mathrm{pH}$ to 6.8 with $\mathrm{KOH}$ & & \\
\hline \multirow[t]{3}{*}{ 1x BRB80 With Supplements } & 1x BRB80 & \multirow[t]{3}{*}{$3.3 \& 4.1-4.2$} & \multirow{3}{*}{$\begin{array}{l}\text { Must be freshly made from the } 5 x \\
\text { BRB80 stock for every experiment. }\end{array}$} \\
\hline & $20 \mu \mathrm{M}$ Taxol (dissolved in DMSO) & & \\
\hline & $1 \mathrm{mM}$ DTT & & \\
\hline \multirow[t]{4}{*}{ 2x Polymerization Mix } & 2x BRB80 (without supplements) & \multirow[t]{4}{*}{3.3} & \multirow{4}{*}{$\begin{array}{l}\text { Flash freeze the mix in small } \\
\text { aliquots and store at }-80^{\circ} \mathrm{C} .\end{array}$} \\
\hline & $2 \mathrm{mM}$ DTT & & \\
\hline & $2 \mathrm{mM}$ Mg-GTP & & \\
\hline & $20 \%$ DMSO & & \\
\hline \multirow[t]{3}{*}{ Reconstitution Buffer } & 1x BRB80 (without supplements) & \multirow[t]{3}{*}{3.1} & \multirow{3}{*}{$\begin{array}{l}\text { Must be freshly made for every } \\
\text { experiment. }\end{array}$} \\
\hline & $1 \mathrm{mM}$ DTT & & \\
\hline & $1 \mathrm{mM}$ Mg-GTP & & \\
\hline
\end{tabular}

Table 2: Buffers for the polymerization of microtubules (Protocol section 3). 


\begin{tabular}{|c|c|c|c|}
\hline Buffer Name & Composition & Step(s) Used & Comment \\
\hline \multirow{3}{*}{$\begin{array}{l}\text { Taxol-Supplemented Lysis } \\
\text { Buffer }\end{array}$} & 1x Lysis Buffer & \multirow[t]{3}{*}{4.1} & \multirow{3}{*}{$\begin{array}{l}\text { Must be freshly made for every } \\
\text { purification. }\end{array}$} \\
\hline & $20 \mu \mathrm{M}$ Taxol (dissolved in DMSO) & & \\
\hline & $1 \mathrm{mM} \mathrm{DTT}$ & & \\
\hline \multirow[t]{4}{*}{ 5x ATP/Taxol Mix } & 1x Lysis Buffer & \multirow[t]{4}{*}{4.2} & \multirow{4}{*}{$\begin{array}{l}\text { Must be freshly made for every } \\
\text { purification. }\end{array}$} \\
\hline & 25 mM Mg-ATP & & \\
\hline & $50 \mu \mathrm{M}$ Taxol (dissolved in DMSO) & & \\
\hline & $5 \mathrm{mM}$ DTT & & \\
\hline
\end{tabular}

Table 3: Buffers for the microtubule affinity purification of functional motor proteins (Protocol section 4).

\begin{tabular}{|c|c|c|c|}
\hline Buffer Name & Composition & Step(s) Used & Comment \\
\hline \multirow[t]{3}{*}{ 20x Origami Folding Buffer } & $100 \mathrm{mM}$ Tris $\mathrm{pH} 8.0$ & \multirow[t]{3}{*}{-} & \multirow{3}{*}{$\begin{array}{l}\text { Can be stored at RT in a properly } \\
\text { sealed container for up to a year. }\end{array}$} \\
\hline & 20 mM EDTA & & \\
\hline & $200 \mathrm{mM} \mathrm{MgCl} 2$ & & \\
\hline \multirow[t]{3}{*}{ 1x Origami Folding Buffer } & $5 \mathrm{mM}$ Tris $\mathrm{pH} 8.0$ & \multirow[t]{3}{*}{$5.1-5.2$} & \multirow{3}{*}{$\begin{array}{l}\text { Make the buffer fresh by diluting } \\
\text { the } 20 x \text { stock with } \mathrm{ddH}_{2} \mathrm{O} \text { before } \\
\text { every experiment. }\end{array}$} \\
\hline & $1 \mathrm{mM}$ EDTA & & \\
\hline & $10 \mathrm{mM} \mathrm{MgCl}_{2}$ & & \\
\hline \multirow[t]{3}{*}{$0.5 \times$ TBE } & 45 mM TrispH 8.0 & \multirow[t]{3}{*}{$5.1-5.2$} & \multirow{3}{*}{$\begin{array}{l}\text { Can be stored at RT in a properly } \\
\text { sealed container for up to a year. }\end{array}$} \\
\hline & 45 mM Boric Acid & & \\
\hline & $1 \mathrm{mM}$ EDTA & & \\
\hline
\end{tabular}

Table 4: Buffers for the production of segmented DNA origami chassis (Protocol section 5). 


\begin{tabular}{|c|c|c|c|}
\hline Buffer Name & Composition & Step(s) Used & Comment \\
\hline \multirow[t]{2}{*}{ DTT-Supplemented BRB80 } & 1x BRB80 & \multirow[t]{2}{*}{7.3} & \multirow{2}{*}{$\begin{array}{l}\text { Must be freshly made before every } \\
\text { TIRF experiment. }\end{array}$} \\
\hline & $1 \mathrm{mM} \mathrm{DTT}$ & & \\
\hline \multirow{3}{*}{$\begin{array}{l}\text { Taxol-Supplemented Lysis } \\
\text { Buffer }\end{array}$} & 1x Lysis Buffer & \multirow[t]{3}{*}{$7.1 \& 7.3$} & \multirow{3}{*}{$\begin{array}{l}\text { Must be freshly made before every } \\
\text { TIRF experiment. }\end{array}$} \\
\hline & $20 \mu \mathrm{M}$ Taxol (dissolved in DMSO) & & \\
\hline & $1 \mathrm{mM} \mathrm{DTT}$ & & \\
\hline \multirow{4}{*}{$\begin{array}{l}\text { Casein-Taxol-Supplemented } \\
\text { Lysis Buffer }\end{array}$} & 1x Lysis Buffer & \multirow[t]{4}{*}{ 7.1-7.3 } & \multirow{4}{*}{$\begin{array}{l}\text { Must be freshly made before every } \\
\text { TIRF experiment. }\end{array}$} \\
\hline & $20 \mu \mathrm{M}$ Taxol (dissolved in DMSO) & & \\
\hline & $1 \mathrm{mM} \mathrm{DTT}$ & & \\
\hline & $\begin{array}{l}\sim 2.5 \mathrm{mg} / \mathrm{ml} \text { Casein (dissolved in } \\
\text { Tris- } \mathrm{HCl} \text { at } \mathrm{pH} 8.0 \text { ) }\end{array}$ & & \\
\hline \multirow[t]{5}{*}{ 1x Lysis Buffer } & 30 mM HEPES (pH 7.4) & \multirow[t]{5}{*}{7.2} & \multirow{5}{*}{$\begin{array}{l}\text { Make this buffer fresh by diluting } \\
\text { the } 5 x \text { stock (recipe detailed in } \\
\text { Table 1) with } d_{d d H_{2}} \mathrm{O} \text {. }\end{array}$} \\
\hline & $50 \mathrm{mM}$ KAcetate & & \\
\hline & $2 \mathrm{mM}$ MgAcetate & & \\
\hline & 1 mM EGTA (pH 7.5) & & \\
\hline & $10 \%$ glycerol & & \\
\hline \multirow[t]{4}{*}{ 4x Energy Mix } & $\begin{array}{l}22.5 \mu \mathrm{L} 1 \times \text { Casein-Taxol- } \\
\text { Supplemenfted Lysis Buffer }\end{array}$ & \multirow[t]{4}{*}{7.3} & \multirow{4}{*}{$\begin{array}{l}\text { Must be freshly made before } \\
\text { every TIRF experiment; volumes } \\
\text { indicated are for a final volume of } \\
25 \mu \mathrm{L} .\end{array}$} \\
\hline & $1 \mu \mathrm{L} 0.1 \mathrm{M} \mathrm{Mg-ATP}$ & & \\
\hline & $1 \mu \mathrm{L} 40 \%$ Glucose & & \\
\hline & $0.5 \mu \mathrm{L} \beta$-Mercaptoethanol & & \\
\hline \multirow[t]{2}{*}{ 4x Scavenger Mix } & $\begin{array}{l}24 \mu \mathrm{L} 1 \times \text { Casein-Taxol- } \\
\text { Supplemented Lysis Buffer }\end{array}$ & \multirow[t]{2}{*}{7.3} & \multirow{2}{*}{$\begin{array}{l}\text { Must be freshly made before } \\
\text { every TIRF experiment; volumes } \\
\text { indicated are for a final volume of } \\
25 \mu \mathrm{L} .\end{array}$} \\
\hline & $1 \mu \mathrm{L} 1 \mathrm{x}$ Oxygen Scavenger System & & \\
\hline
\end{tabular}

Table 5: Buffers and mixes for the motor-ensemble motility TIRF assay (Protocol section 7). Details on the Oxygen Scavenger System used to make the Scavenger Mix can be found elsewhere ${ }^{17}$.

\section{Discussion}

The molecular construction techniques of DNA origami provide a unique way to construct motor ensembles with defined architectures, motor numbers, and types, enabling studies of how emergent behavior arises from specific motor configurations ${ }^{31}$. As structural and cellular studies continue to elucidate examples of cytoskeletal motors working in teams, techniques for isolating and investigating the biophysical and biochemical mechanisms of motors in ensembles are growing in utility. For example, cryo-EM has shown that dynactin can bind 2 individual dynein motors, and that such pairings have different motility than the individual motors ${ }^{10}$. In addition, DNA-based construction was used to determine if mammalian dynein, when activated by dynactin and bicD2, could match the force of kinesin-1 in a tug of war scenario ${ }^{14}$. In another mixed-motor study, DNA origami was used to decouple the effects of opposite polarity motors and their regulatory binding proteins by spatially separating them on an origami structure ${ }^{15}$. As more structural and regulatory determinants of motility are found, DNA-origami-based techniques should prove useful in determining the specific biochemical and biophysical contributors to the emergent motility of motor ensembles. The molecular construction techniques enabled by DNA origami are particularly useful because the emergent phenomenological outcomes of ensembles are difficult to predict. This is due in part to the myriad factors that contribute to the motility of the individual motors within the ensemble $5,6,31$.

Examples of our previous structures include monolithic rods and segmented rods with variable rigidity. Current efforts explore spherical structures as well ${ }^{25}$. Others have employed morphologies such as planar structures and rods ${ }^{22,24}$. Likewise, by using motor handles with orthogonal DNA sequences, different types of motors can be bound to the same chassis structure ${ }^{7,14,15,18}$. This approach enables studies of the opposing actions of dyneins and kinesins, minus- and plus-end directed kinesins, and minus- and plus-end directed myosins. It also enables the introduction of a mutant among otherwise wild-type ensembles, allowing the specific biochemical contributors to the emergent motility to be deciphered ${ }^{7}$. Because of the ability to bind multiple fluorophores to each individual structure, imaging in TIRF and subsequent analysis by kymography or particle tracking is possible. Previous reports show analysis of kymography data and statistical evaluation of chassis structures with variable compliance ${ }^{8}$. While cytoskeletal motors have proven to be an exciting early application of using DNA origami as a molecular breadboard $^{32}$, other proteins and protein systems will also benefit from these methods. 


\section{Disclosures}

The authors have nothing to disclose.

\section{Acknowledgments}

We thank K. Chau, J. Morgan, and A. Driller-Colangelo for contributing to the techniques of the segmented DNA origami chassis. We also thank former members of the Reck-Peterson and Shih laboratories for helpful discussions and contributions to the original development of these techniques. We thank J. Wopereis and the Smith College Center for Microscopy and Imaging and L. Bierwert and the Smith College Center for Molecular Biology. We gratefully acknowledge the NSF MRI program for the acquisition of a TIRF microscope.

\section{References}

1. Vale, R. D. The molecular motor toolbox for intracellular transport. Cell. 112 (4), 467-480 (2003).

2. Cianfrocco, M. A., DeSantis, M. E., Leschziner, A. E., Reck-Peterson, S. L. Mechanism and regulation of cytoplasmic dynein. Annual Review of Cell and Developmental Biology. 31 (1), 83-108 (2015).

3. Roberts, A. J., Kon, T., Knight, P. J., Sutoh, K., Burgess, S. A. Functions and mechanics of dynein motor proteins. Nature Reviews Molecular Cell Biology. 14 (11), 713-726 (2013).

4. Hancock, W. O. The Kinesin-1 Chemomechanical Cycle: Stepping Toward a Consensus. Biophysical Journal. 110 (6), $1216-1225$ (2016).

5. McLaughlin, R. T., Diehl, M. R., Kolomeisky, A. B. Collective dynamics of processive cytoskeletal motors. Soft Matter. 12 (1), 14-21 (2016).

6. Hancock, W. O. Bidirectional cargo transport: moving beyond tug of war. Nature Reviews Molecular Cell Biology. 15 (9), $615-628$ (2014).

7. Derr, N. D. et al. Tug-of-war in motor protein ensembles revealed with a programmable DNA origami scaffold. Science. 338 (6107), $662-665$ (2012).

8. Driller-Colangelo, A. R., Chau, K. W. L., Morgan, J. M., Derr, N. D. Cargo rigidity affects the sensitivity of dynein ensembles to individual motor pausing. Cytoskeleton. 73 (12), 693-702 (2016).

9. Torisawa, T. et al. Autoinhibition and cooperative activation mechanisms of cytoplasmic dynein. Nature Cell Biology. 16 (11), $1118-1124$ (2014).

10. Urnavicius, L. et al. Cryo-EM shows how dynactin recruits two dyneins for faster movement. Nature. 554 (7691), 202-206 (2018).

11. Toropova, K., Mladenov, M., Roberts, A. J. Intraflagellar transport dynein is autoinhibited by trapping of its mechanical and track-binding elements. Nature Structural \& Molecular Biology. 24 (5), 461-468 (2017).

12. Furuta, K., Furuta, A., Toyoshima, Y. Y., Amino, M., Oiwa, K., Kojima, H. Measuring collective transport by defined numbers of processive and nonprocessive kinesin motors. Proceedings of the National Academy of Sciences of the United States of America. 110 (2), $501-506$ (2013).

13. Rogers, A. R., Driver, J. W., Constantinou, P. E., Kenneth Jamison, D., Diehl, M. R. Negative interference dominates collective transport of kinesin motors in the absence of load. Physical Chemistry Chemical Physics. 11 (24), 4882-4889 (2009).

14. Belyy, V. et al. The mammalian dynein-dynactin complex is a strong opponent to kinesin in a tug-of-war competition. Nature Cell Biology. 18 (9), 1018-1024 (2016).

15. Roberts, A. J., Goodman, B. S., Reck-Peterson, S. L. Reconstitution of dynein transport to the microtubule plus end by kinesin. eLife. 3 , e02641 (2014).

16. Reck-Peterson, S. L. et al. Single-molecule analysis of dynein processivity and stepping behavior. Cell. 126 (2), $335-348$ (2006).

17. Gennerich, A., Reck-Peterson, S. L. Probing the force generation and stepping behavior of cytoplasmic Dynein. Methods in Molecular Biology. 783 (Chapter 4), 63-80 (2011).

18. Goodman, B. S., Reck-Peterson, S. L. Engineering defined motor ensembles with DNA origami. Methods in Enzymology. 540, 169-188 (2014).

19. Rao, L., Hülsemann, M., Gennerich, A. Combining Structure-Function and Single-Molecule Studies on Cytoplasmic Dynein. In: Peterman E. (eds), Single Molecule Analysis. Methods in Molecular Biology., vol. 1665. Humana Press, New York, NY. (2018).

20. Qiu, W., Derr, N. D., et al. Dynein achieves processive motion using both stochastic and coordinated stepping. Nature Structural \& Molecular Biology. 19 (2), 193-200 (2012).

21. Gietz, R.D. Yeast Transformation by the LiAc/SS Carrier DNA/PEG Method. In: Smith J., Burke D. (eds.), Yeast Genetics. Methods in Molecular Biology(Methods and Protocols)., vol. 1205. Humana Press, New York, NY. (2014).

22. Hariadi, R. F., Cale, M., Sivaramakrishnan, S. Myosin lever arm directs collective motion on cellular actin network. Proceedings of the National Academy of Sciences of the United States of America. 111 (11), 4091-4096 (2014).

23. Krementsova, E. B., Furuta, K., Oiwa, K., Trybus, K. M., Ali, M. Y. Small teams of myosin Vc motors coordinate their stepping for efficient cargo transport on actin bundles. The Journal of Biological Chemistry. 292 (26), 10998-11008 (2017).

24. Hariadi, R. F. et al. Mechanical coordination in motor ensembles revealed using engineered artificial myosin filaments. Nature Nanotechnology. 10 (8), 696-700 (2015).

25. Hu, J. J., Morgan, J., Yang, Y., Lin, C., Derr, N. D. Spherical DNA Origami as a Programmable Cargo Structure for Investigating the Emergent Motility of Dynein and Kinesin Ensembles. Biophysical Journal. 116 (3), 408A (2019).

26. Wagenbauer, K. F. et al. How We Make DNA Origami. Chembiochem. 18 (19), 1873-1885 (2017).

27. Lin, C., Perrault, S. D., Kwak, M., Graf, F., Shih, W. M. Purification of DNA-origami nanostructures by rate-zonal centrifugation. Nucleic Acids Research. 41 (2), e40 (2013).

28. Ke, Y., Voigt, N. V., Gothelf, K. V., Shih, W. M. Multilayer DNA origami packed on hexagonal and hybrid lattices. Journal of the American Chemical Society. 134, 1770-1774 (2012).

29. Schneider, C. A., Rasband, W. S., Eliceiri, K. W. NIH Image to ImageJ: 25 years of image analysis. Nature Methods. 9 (7), $671-675$ (2012).

30. Reck-Peterson, S. L., Derr, N. D., Stuurman, N. Imaging single molecules using total internal reflection fluorescence microscopy (TIRFM). Cold Spring Harbor Protocols. 2010 (3), pdb.top73-pdb.top73 (2010). 
31. Derr, N. D. Interactions of Multiple Dynein Motors Studied Using DNA Scaffolding. In Hirose, K. (ed.), Handbook of Dynein, $2^{\text {nd }}$ Edition. Stanford Publishing (2019).

32. Rothemund, P. W. K. Folding DNA to create nanoscale shapes and patterns. Nature. 440 (7082), 297-302 (2006). 